\title{
Juventude e política na experiência de dez anos do Parlamento Jovem Brasileiro: confiança, participação e engajamento político dos egressos
}

\section{Resumo}

Neste artigo, analisamos os impactos do Parlamento Jovem Brasileiro (PJB), programa de simulação parlamentar juvenil da Câmara dos Deputados brasileira, a partir do teste de duas hipóteses. A primeira avalia se a experiência interferiu na confiança política e a segunda examina se o PJB estimulou o engajamento e a participação política dos jovens. O estudo resulta de pesquisa concluída em 2014, baseada em levantamento do tipo survey, com questionário aplicado on-line com os egressos das edições de 2004 a 2013 (10 eventos). Do total de 762 de ex-participantes, 173 responderam o questionário (22,70\% do universo estudado). As conclusões confirmam as duas hipóteses testadas empiricamente. Fica evidente, nos resultados da pesquisa, um aumento expressivo no nível de confiança e de engajamento político dos egressos do PJB, com destaque para a participação político-partidária.

Palavras-chave: Juventude e política. Confiança política. Engajamento juvenil. Sociologia da Juventude. Parlamento Jovem Brasileiro. Câmara dos Deputados. Brasil.

\footnotetext{
"Centro de Formação da Câmara dos Deputados, Brasil.
} 


\title{
Youth and politics in the ten-year experience of the Brazilian Youth Parliament: trust, participation and political engagement of former participants
}

\begin{abstract}
In this article, we analyse, based on the test of two hypotheses, the impacts of the Brazilian Youth Parliament (Parlamento Jovem Brasileiro - PJB), a juvenile parliamentary simulation program of the Brazilian Chamber of Deputies. The first test is aimed to examine whether the experience has influenced in political trust, and the second one to examine whether the PJB has encouraged youth political engagement and participation. This study draws on a research completed in 2014, based on a survey, using a questionnaire applied online to former participants of PJB, considering editions from 2004 to 2013 (10 events). Of the 762 former participants, 173 answered the questionnaire (22.70\% of the universe studied). The conclusions confirm the two hypotheses tested empirically. Research findings show a significant increase in the level of trust and political engagement of PJB alumni, with emphasis on political party participation.
\end{abstract}

Keywords: Youth and politics. Political trust. Youth engagement. Sociology of youth. Brazilian Youth Parliament. Chamber of Deputies. Brazil. 


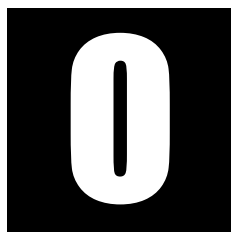

estudo tem como objetivo avaliar os impactos do Parlamento Jovem Brasileiro (PJB), programa de simulação parlamentar juvenil da Câmara dos Deputados brasileira, a partir do teste de duas hipóteses. A primeira avalia se a experiência interferiu na confiança política dos participantes. A segunda avalia se o PJB estimulou o engajamento e a participação política dos jovens, no plano institucional.

A análise é baseada em levantamento do tipo survey, com questionário aplicado on-line, nos meses de outubro e novembro de 2014. Os ex-participantes das edições de 2004 a 2013 (10 eventos) foram contatados por meio de e-mail e Facebook, quando foram convidados a preencher um questionário com questões abertas e fechadas. Do total de 762 jovens que participaram do projeto nas dez edições mencionadas, 173 responderam o questionário, representando $22,70 \%$ do universo estudado.

Intentou-se a realização de um censo junto aos participantes, mas ao final da coleta de dados, optou-se pela exclusão das respostas relativas aos dois anos iniciais (2004 e 2005), em vista do baixo índice de respostas advindo da dificuldade de contato com esse grupo. Assim, a análise final contempla oito anos de execução do PJB, isto é, de 2006 a 2013, totalizando 166 respondentes, o que corresponde a $27,43 \%$ do total de egressos das oito edições mencionadas (universo de 605 participantes). Essa decisão foi tomada com base nas diversas características desse público analisado no estudo, entre elas, gênero, idade, moradia em capital ou cidade do interior e escolaridade ${ }^{1}$, já que a análise de uma amostra

\footnotetext{
1 Não foram analisados fatores socioeconômicos, pois essa questão poderia prejudicar o levantamento de dados devido ao constrangimento que acarretaria na coleta. Outro fator não estudado foi a proveniência dos egressos de escolas públicas ou particulares, já que os ex-participantes das edições mais antigas passaram por outras instituições também públicas ou privadas como universidades e outras instituições de ensino, o que inviabilizaria uma análise isolada dessa característica.
} 
com apenas duas (2004) ou cinco (2005) respostas não abarcaria esses variados fatores necessários à compreensão dos fenômenos estudados.

A pesquisa tem como fundamentação teórica a sociologia da juventude e a sociologia política. A primeira contribui com a ideia de que, cada vez mais, os jovens passam a ser caracterizados como um grupo social plural e emergente, com diferentes formas de engajamento e de participação, variados repertórios de ação coletiva e múltiplas agendas. A segunda contribui com estudos sobre confiança política e engajamento político juvenil. Estudos empíricos apontam para uma multiplicidade de formas de participação e de engajamento social dos jovens, os quais enveredam por caminhos diversos, sejam os da política institucional, sejam os da ação militante no trabalho social voluntário.

\section{Confiança política}

A confiança institucional é um dos elementos centrais da modernidade, na forma de credibilidade pública, o que se reflete diretamente na imagem e na reputação de governos e instituições públicas. Trata-se de "uma forma de fé na qual a segurança adquirida em resultados prováveis expressa mais um compromisso com algo do que apenas uma compreensão cognitiva" (Giddens, 1990, p. 29). Dessa forma, a confiança expressa no nível de adesão ao regime democrático e na utilização das instituições oficiais constitui um fator simbólico de suma importância para a estabilidade política e institucional.

Como assinala Miguel, há uma "deterioração da adesão popular às instituições representativas" (2003, p. 123), especialmente sob o ponto de vista liberal de democracia adotado por autores como Schumpeter. Em outra obra, Miguel faz uma síntese dos estudos que apontam uma crise da representação ou da democracia nos países ocidentais, nos anos 70 e 90 
do século passado, e que revelam "o descrédito generalizado das instituições representativas entre os cidadãos comuns" (Miguel, 2005, p. 27). A confiança, portanto, pode se tornar um antídoto às recorrentes crises das democracias (McCoy, 2000).

Vários outros autores (Porto, 1996; Boschi, 2004; Stoker, 2006; Dalton, 2007; Moisés, 2009) enfatizam a crise de descrédito por que passam as instituições políticas contemporâneas. Pesquisas recentes revelam que o nível de confiança da população nas instituições políticas nunca foi tão baixo, especialmente em relação às Casas Legislativas (Leston-Bandeira, 2012). Essa desconfiança nos políticos, o ceticismo em relação a instituições democráticas e a desilusão com o processo democrático chegam a ser apontadas por Dalton (2007) e Stoker (2006) como o grande desafio das democracias contemporâneas, já que é comum a todas as democracias industriais avançadas. A desconfiança é apontada em vários estudos da ciência política ${ }^{2}$ como efeito da percepção da corrupção e ênfase dos media em informações sobre condutas inadequadas de parlamentares e figuras da vida pública (Power; Jaminson, 2005). O desenvolvimento de uma cidadania cada vez mais crítica e vigilante também é apontado como um dos fatores do aumento da desconfiança (Ribeiro, 2011).

Boschi (2004, p. 3) explica que isso se deve à ausência de resultados substantivos das instituições democráticas, que correspondam às expectativas dos cidadãos em relação a mudanças, revelando um descompasso muito grande entre o que se chama de democracia formal e substantiva no Brasil, e na América Latina em geral, com implicações sobre a qualidade da democracia. Ainda que certo grau de desconfiança seja necessário para garantir a fiscalização ou para estimular reformas e melhorias no processo democrático, a confiança é importante, se não para a existência

2 Para um panorama desses estudos, ver Power e Jaminson, 2005; Colen, 2010; Lopes, 2004; Ribeiro, 2011, entre outros. 
da democracia, ao menos para sua vitalidade (Tilly, 2008; Norris, 1999; Lijphart, 2001).

Dessa forma, as instituições políticas surgem como "fatores de diminuição de risco" (Feres Jr.; Eisenberg, 2006, p. 471), pois seu funcionamento adequado inibe previamente os potenciais quebradores de confiança e possibilita a reparação dos danos causados pelo não cumprimento das regras por alguns. Para os autores, as instituições servem como espaço de discussão e deliberação de três tipos de demandas sociais em um regime democrático: reconhecimento, redistribuição e revisão das regras das próprias instituições (2006, p. 473).

O fato é que o debate sobre democracia está diretamente relacionado com a questão da confiança do cidadão nas instituições. A discussão está conectada à ideia de que a confiança da população nas instituições de seus países ou comunidades é um aspecto essencial para a legitimidade do regime político e, portanto, para a estabilidade do sistema social. De maneira geral, podemos dizer que quanto mais confiança nas instituições, maiores as chances de desenvolvimento de um regime democrático satisfatório para a população (Dahl, 1989; Norris, 1999; Lijphart, 2001; Tilly, 2008). No sistema representativo, com parlamentos, isso adquire ainda mais importância.

Estudos empíricos internacionais mostram que, embora a confiança nas instituições políticas esteja em declínio, o mesmo não se verifica quando se trata das pesquisas sobre a adesão dos cidadãos à democracia. A interpretação do fenômeno é complexa e multifacetada. Por um lado, há análises que associam a desconfiança ao avanço da cidadania crítica, como é o caso de Pipa Norris (1999). Para a autora, quanto mais críticos os cidadãos se tornam, mais exigem dos representantes e das instituições. Em perspectiva contrária, o argumento mais citado baseia-se na visão de Clauss Offe (1999), segundo o qual a desconfiança generalizada dos ci- 
dadãos nas instituições e nos governantes pode comprometer a relação entre governantes e governados, uma das bases de sustentação dos regimes democráticos.

No caso do Brasil e das demais jovens democracias latino-americanas, os estudiosos apontam que elas padecem da "síndrome de desconfiança generalizada" (Power; Jaminson, 2005; Colen, 2010; Lopes, 2004; Ribeiro, 2011). Mas seriam as causas da desconfiança política na América Latina as mesmas identificadas nas democracias avançadas? Segundo Ribeiro (2011), as razões são distintas e as explicações devem ser buscadas no contexto cultural e histórico. Enquanto nas democracias consolidadas a desconfiança é fruto do elevado nível de escolarização e informação dos cidadãos críticos, nas jovens democracias latinas, a explicação estaria na desilusão dos cidadãos com o funcionamento concreto das instituições políticas, principalmente os parlamentos. Em um ambiente social marcado por extremas desigualdades, a percepção dos cidadãos de que os sistemas político e econômico "beneficiam diferentemente os indivíduos pode levar a uma sensação de que as instituições não são confiáveis" (Colen, 2010, p. 5). Essa "síndrome cultural latinoamericana" teria se enraizado no modo de vida dos cidadãos dessas jovens democracias, estruturando, assim, "uma convivência marcada pela desconfiança entre as pessoas e, por decorrência, pela desconfiança em relação às instituições do Estado" (Colen, 2010, p. 4).

O Brasil segue em percursos interpretativos distintos das democracias industriais avançadas. A baixa confiança, nesse cenário, mostra-se próxima a sentimentos de apatia e distanciamento com relação aos aspectos políticos, não refletidos em atitudes de crítica para com o sistema. Esses apontamentos nos levam a confirmar a necessidade de se pautar os estudos sobre cultura política com base em suas realidades contextuais, distantes dos padrões vigentes em democracias industriais avançadas. 
Outra observação pertinente é a de que os parlamentos não são o foco exclusivo da desconfiança da população, mas são um ponto de concentração de desconfiança. Norris (2011, p. 103) chama atenção, em estudo comparativo de 11 países, para o fato de que a confiança nesta instituição específica apresenta queda significativa ao longo do tempo.

Em relação à juventude, levantamentos mostram até $82 \%$ de desinteresse dos jovens pela política em suas modalidades institucionalizadas ${ }^{3}$ (Baptista et al., 2013). Isso se deve, principalmente, à recorrente associação entre política e corrupção, o que reforça o pessimismo e a descrença da juventude:

Descrentes da política, desconfiados das instituições representativas, suspeitosos em relação à organização do processo eleitoral e com poucas expectativas de serem ouvidos pelas lideranças, os jovens acabam por participar pouco da vida política (...) Apenas 18,8\% deles participam de organizações como partidos políticos, sindicatos, organizações não governamentais, associações de bairro, religiosas ou estudantis (...) O ingresso em partidos políticos $(1,4 \%)$ ou mesmo em associações estudantis $(2,6 \%)$ é praticamente nulo (Telles; Dias, 2010, p. 97).

Diante desse cenário, importa avaliar como o PJB interfere na relação dos egressos com a política, sob o ângulo específico da confiança no Poder Legislativo e nos partidos políticos.

\section{Juventude e participação política}

No caso da juventude, estudos empíricos apontam para uma multiplicidade de formas de participação e de engajamento político e social que enveredam por caminhos diversos, sejam os da política insti-

\footnotetext{
${ }^{3}$ Trata-se da pesquisa Juventude, Participação e Voto, realizada por pesquisadores da Universidade Federal de Minas Gerais, em 2010. Disponível em:

http://www.opiniaopublica.ufmg.br/pesquisas_detalhe.php?id=41
} 
tucional, sejam os da ação militante no trabalho social voluntário (Castro, 2008; Mayorga; Castro; Prado, 2009). Outra característica do engajamento político juvenil é que nem sempre o sentido político das ações aparece de forma ostensiva, ou seja, nem sempre é explicitado ou admitido pelos jovens. Isso mostra que as formas convencionais da ação política permanecem em tensão com outras escolhas de engajamento e de participação na sociedade.

O engajamento juvenil, contudo, é impulsionado pelo idealismo, conforme registra pesquisa de Castro (2008), marcado pela convergência na defesa de causas comuns, independentemente da orientação ideológico-partidária. Essa convergência é expressa, por exemplo, no combate à corrupção, na luta pela redução das desigualdades sociais e na reivindicação de melhores serviços públicos, especialmente educação e saúde. Isso significa que a militância juvenil nos partidos políticos e nos movimentos estudantis é pautada por uma visão crítica da sociedade e pela participação entendida como forma de promover uma ampla transformação social (Castro, 2008, p. 257).

Essa particularidade no modo juvenil de encarar a participação é um dos fatores que explicam a suspeita deles em relação à política institucionalizada. Além disso, as disputas, os debates e conflitos característicos da esfera partidária, por exemplo, são vistos como impedimentos para o engajamento e a participação no plano institucional, pois implica negociações e acordos suspeitos. Tais arranjos são considerados instrumentos para a máquina partidária, algo que se distancia do ideal de transformação sociopolítica almejada. Por essa razão, os jovens preferem "uma via direta de ação e de participação na sociedade, em que podem constatar, por eles mesmos, os efeitos do que fazem, sem intermediações" (Castro, 2008, p. 263). 
Dados da Pesquisa Nacional sobre o Perfil e a Opinião dos Jovens Brasileiros ${ }^{4}$ mostram que $54 \%$ deles nunca participou de nenhuma atividade política no âmbito institucional e que $45 \%$ reconhece as mobilizações de rua, protestos, manifestações e outras ações diretas como a via mais indicada para a solução de problemas sociais. Pesquisa realizada pelo Instituto Data Popular, em 2014, revela que 59\% dos jovens brasileiros acredita que o Brasil seria melhor se não houvesse nenhum partido político (Rodrigues, 2014). Apesar da descrença, a pesquisa revela que a juventude é mais informada que seus pais e tem peso decisivo na eleição.

Os dados estão em consonância com as tendências indicadas pela literatura especializada. Os estudos registram um refluxo nas formas convencionais de participação política entre os jovens e um crescimento na adesão às modalidades de mobilização caracterizadas pela contestação e o protesto (Ribeiro, 2012). As práticas políticas estabelecidas são nitidamente rechaçadas pelos movimentos protagonizados por jovens, levando-os a negar que fazem política, mesmo quando existem características tipicamente políticas, como mostra o levantamento coordenado por Mayorga, Castro e Prado (2012). Isso implica a rejeição à política partidária e às lógicas dominantes nas eleições e no cotidiano das câmaras de vereadores, assembleias legislativas, Câmara dos Deputados e Senado Federal. O reflexo direto disso é a baixa confiança nas instituições legislativas, com registro de 4,4 numa escala de zero a 10 (Baptista et al., 2013, p. 129). O que explica tal performance em termos de confiança no Poder Legislativo (em todos os níveis), segundo os autores citados, é a recorrente associação entre política e corrupção, o que reforça o pessimismo e a descrença da juventude (Telles; Dias, 2010).

Embora a juventude seja representada sociologicamente como "uma categoria relacional que posiciona os indivíduos como pertencentes

${ }^{4}$ Pesquisa realizada pela Secretaria Nacional da Juventude. Disponível em: http://www.polis. org.br/uploads/1982/1982.pdf 
a uma dada faixa etária" (Gohn, 2013, p. 205), o que as pesquisas recentes mostram é que existem várias juventudes. Cada vez mais, os jovens passam a ser caracterizados como um grupo social plural e emergente (Malfitano, 2011) ${ }^{5}$, com diferentes formas de engajamento e de participação, variados repertórios de ação coletiva e múltiplas agendas (Dayrell; Moreira; Stengel, 2011), o que requer olhares menos simplificadores. Isso dificulta a identificação de um padrão de engajamento e de participação, além de apontar para a dificuldade de se registrarem tendências uniformes e estanques (Ribeiro; Lanes; Carrano, 2006).

É como resume Nascimento (2012, p. 321):

A participação política de jovens é caracterizada por múltiplas formas de participar que vão além das formas convencionais. São mais flexíveis, pontuais e esteticamente mais criativas. Os jovens se mobilizam de outras formas para fins que buscam assegurar sua representação e visibilidade nas esferas institucionalizadas da política. Isto é, os jovens não estão tão fora do escopo institucional da política, tampouco recusam essa forma de participação. Porém, as formas mais flexíveis, não convencionais, mais abertas podem revelar mais propriamente a crítica e a desconfiança nas instituições políticas convencionais do que uma postura de negação dessas instituições.

Bordenave (2002) aponta duas ordens de fatores que funcionam como motivação primária para influenciar o engajamento e a participação juvenil. A primeira teria uma base afetiva, devido à adesão e o envolvimento prévio de familiares, amigos e pessoas pelas quais os jovens nutrem sentimentos de admiração. A segunda teria uma base instrumental, ou seja, quando a motivação é nutrida por motivos que são vislumbrados

\footnotetext{
5 Ao mesmo tempo em que impera essa visão plural da juventude sob a ótica sociocultural, a autora alerta: "observa-se uma uniformização da ideia de juventude, considerando-a indistintamente como um grupo único, para o qual se lança o olhar como 'problema político' necessitando de intervenção e de controle" (Malfitano, 2011, p.525).
} 
pelos próprios jovens como forma de ver suas reivindicações atendidas, a exemplo de movimentos estudantil e ecológico.

Ao contrário do que diz o senso comum, estudos empíricos sobre engajamento e participação juvenil no Brasil revelam um perfil de jovens altamente engajados em atividades sociais, comunitárias, ambientais e em projetos de interesse local. Contudo, as mesmas pesquisas apontam para um baixo interesse na participação política convencional, ou seja, aquela pela via institucional dos partidos e do voto (Rique et al., 2009). Esse quadro se explica pela elevada desconfiança na política, em contraposição a um cenário de elevada confiança na família, nas igrejas e nas entidades não governamentais (Paiva, 2010). Os estudos mostram que a política "não parece interpelar os jovens como atividade criadora e transformadora do mundo" (Castro, 2009, p. 480). O fato é que, segundo a última autora citada, a política como o campo da diferença e da contradição requer um certo nível de competência cognitiva que nem sempre é possível da parte dos jovens. Além disso, há que se considerar ainda a relevância dos contextos privados de socialização política aos quais estão expostos os jovens desde sua infância:

A perspectiva da socialização pressupõe uma determinada concepção do processo de subjetivação em que o trajeto biográfico está balizado por pontos de partida e pontos de chegada ao longo do qual o indivíduo está sujeito a um processo de transformação, seja por práticas sociais formais de ensino-aprendizagem, seja por processos familiares que deixam marcas originais para futuras ações e atitudes (CASTRO, 2009, 482).

Conforme aponta Okado (2013), há uma variedade de estudos empíricos que confirmam o diagnóstico de uma queda no engajamento político juvenil na política institucional. Uma das referências principais sobre o assunto é o estudo de Norris (2003). Para a autora, a análise da participação política juvenil deve considerar três ordens de efeitos. A primei- 
ra compreende os efeitos geracionais, que explicariam maior ou menor interesse em política, de acordo com a faixa etária. A segunda abrange os "efeitos de ciclos de vida", ou seja, explica eventuais mudanças nos critérios e prioridades das escolhas políticas em função do ciclo de vida do cidadão. O terceiro abarca os "efeitos de período", isto é, como as preferências e escolhas variam em função da conjuntura política e econômica, o que requer análise comparada de diferentes períodos da vida do cidadão e não apenas a fase juvenil.

Ao realizar estudo empírico no contexto brasileiro, com base no modelo proposto por Pipa Norris, Okado (2013) aponta duas perspectivas analíticas para este fenômeno. A primeira tem como base explicações centradas na transição geracional, ou seja, o desinteresse dos jovens pela política institucionalizada seria decorrência de uma certa fase do ciclo de vida social, focado em determinadas prioridades valorativas dos jovens. A segunda abordagem tem como eixo explicativo os estudos sobre socialização política e sustenta a tese de que as diferenças notadas nos padrões de participação política em faixas etárias estão relacionadas com o aprendizado que se desenvolveu no seio da família e das relações interpessoais. Assim, os repertórios de participação política "seriam construídos no decorrer da vida, marcados pelas trocas simbólicas e pelos processos de aquisição de competências cognitivas ao longo do desenvolvimento individual" (Okado, 2013, p. 38).

A literatura internacional sobre comportamento político registra que a faixa etária é uma variável de grande relevância quando se trata de interesse por política e formas de participação, com base no argumento de que "os recursos materiais e cognitivos relacionados à participação, bem como os vínculos sociais, se acumulam no decorrer do tempo" (Okado, 2013, p. 41). Assim, o jovem se interessaria menos por política, mas conforme adquire maiores níveis educacionais, amplia o seu interesse 
quando adulto e se desinteressa na terceira idade devido à perda de seus vínculos sociais. Trata-se daquilo que Milbrath e Goel (1977) denominam "efeito curvilíneo" entre interesse por política e idade. Logo, "existe um desencanto com este instrumento de participação ao longo da vida" (Okado, 2013, p.44).

O componente geracional, portanto, revela-se uma variável relevante no contexto recente. Por outro lado, o mesmo autor chama atenção para a necessidade de estudos empíricos que confirmem a tendência apontada no cenário brasileiro, uma vez que dados coletados a partir dos levantamentos do Latinobarômetro mostram que ainda temos percentuais e padrões "muito semelhantes entre os estratos etários" (Ribeiro, 2013, p. 30), diferentemente do que mostram estudos empíricos estrangeiros. Tal constatação leva ao questionamento acerca da emergência de uma cidadania mais crítica e contestatória entre os jovens brasileiros:

Apesar de pesquisadores apresentarem evidências consistentes sobre uma mudança geracional no padrão de participação em algumas democracias consolidadas (...), esse não é um fenômeno verificável entre o público brasileiro (...). Comparando as frequências de comportamentos e algumas atitudes de distintas faixas etárias do público nacional, não foram encontradas diferenças importantes, o que nos leva a conclusão de que não podemos falar de uma juventude mais crítica em relação às formas convencionais de envolvimento ou mais engajada em modalidades ligadas ao protesto político (Ribeiro, 2013, p. 33).

Outra observação relevante sob a ótica geracional é o potencial de novidade e de criatividade que é inerente aos jovens, uma vez que eles "constituem-se enquanto novidade histórica" em relação às demais gerações e "às tradições culturais que se pretendem hegemônicas, pois enquanto nova geração a juventude está fora da lógica estruturante do mundo já instituído" (Zitkoski; Hammes, 2014, p. 136). 
Considerando que a educação também contribui para a socialização política (Castro, 2009), caberia indagar até que ponto uma iniciativa de educação para a democracia, como é o caso do PJB, pode influenciar a conduta de jovens? Que aspectos podem ser afetados no que se refere à participação política institucional? Os conhecimentos e a experiência adquirida no PJB diferenciam o comportamento dos egressos em relação ao perfil dos cidadãos verificado em estudos semelhantes?

\section{O parlamento jovem brasileiro}

O PJB é um projeto anual de simulação parlamentar juvenil. Estudantes do ensino médio e técnico de escolas públicas e privadas, entre 16 e 22 anos ( $2^{\circ}$ ou $3^{\circ}$ anos), são convidados a participarem de um concurso de projetos de lei, por meio do qual são selecionados 78 jovens que têm a oportunidade de passar por um processo de formação e prática parlamentar simulada, durante uma semana, na Câmara dos Deputados.

A iniciativa foi idealizada pelo então Deputado Federal Lobbe Netto (PSDB/SP) e instituído como um projeto institucional da Câmara dos Deputados por meio da resolução 12/2003. Em novembro daquele ano, previa-se inicialmente um projeto a ser desenvolvido em parceria com as instituições representativas estudantis (UNE e UBES) que promoveriam a seleção por meio de eleições abertas aos estudantes. Percebe-se, assim, que o objetivo inicial do projeto era de formar líderes políticos, dada essa intenção de se vincular ao movimento estudantil. Também previa-se alternância de turmas do ensino médio e do ensino superior a cada ano ${ }^{6}$. Porém, já na primeira edição do projeto, em 2004, foi iniciado com outra configuração, bastante semelhante ao formato atual, direcionado aos

\footnotetext{
${ }^{6}$ Regimento interno do PJB ainda mantém essas intenções iniciais apesar das modificações por que passou o projeto: http://www2.camara.leg.br/responsabilidade-social/parlamentojovem/ regimento-interno-do-parlamento-jovem-brasileiro
} 
jovens do ensino médio e com seleção realizada por meio de concurso de redação legislativa. Apesar de alterações pontuais de procedimentos, seja na seleção ou nas atividades didáticas e de simulação, o projeto vem tendo uma constância de seus procedimentos e conteúdos, o que facilita uma análise histórica dos seus resultados. Desde que foi criado, o PJB já realizou onze edições (2004-2015).

Apesar de não se ter efetivada a participação das instituições estudantis, uma das características do projeto está no envolvimento interinstitucional. O Conselho Nacional de Secretários de Educação (Consed) tem papel essencial na difusão do programa nacionalmente. As secretarias estaduais de educação realizam a divulgação do projeto por meio de releases pré-elaborados, spots de rádio e peças publicitárias impressas, oferecidos pela Câmara dos Deputados, e recebem as inscrições com os projetos de lei para uma primeira avaliação de questões documentais obrigatórias. O servidor indicado por cada secretaria de educação, também faz uma primeira seleção dos projetos com base em critérios pré-estabelecidos e os escolhe em quantidade de até 4 vezes o número de vagas de cada estado. A seleção final dos projetos é feita por uma comissão de servidores da Câmara dos Deputados.

No mês de março anterior a cada edição, é realizado um encontro com os colaboradores dos estados com diferentes objetivos: avaliação da edição anterior, conscientização quanto à importância da educação política, busca de compromisso com as etapas de organização do programa e apresentação da campanha de divulgação da edição seguinte.

A simulação inclui eleição da Mesa Diretora, debates nas comissões temáticas, além de votação em plenário de proposições, sendo todas as atividades organizadas conforme o Regimento Interno do PJB, homologado pelo Ato da Mesa Diretora da Câmara no 49/2004. 


\section{Análise dos resultados}

A análise dos dados inicia com a caracterização da amostra estudada, com ênfase para os seguintes aspectos: faixa etária dos respondentes, sexo, ano de participação, região e escolaridade. O objetivo dessas informações é contextualizar as respostas dos sujeitos da pesquisa.

A amostra estudada inclui participantes de 17 a 29 anos, sendo cerca de $52 \%^{7}$ mulheres e $48 \%$ homens (Tabela 1 ).

Tabela 1. Idade e sexo dos informantes

\begin{tabular}{c|c|c|c|c|c}
\hline Faixa etária & $\mathbf{N}$ & $\mathbf{\%}$ & Gênero & $\mathbf{N}$ & $\mathbf{\%}$ \\
\hline 17 a 20 & 64 & 38,55 & Masculino & 86 & 48,19 \\
\hline 21 a 24 & 77 & 46,38 & Feminino & 80 & 51,80 \\
\hline 25 a 29 & 25 & 15,06 & - & - & - \\
\hline Total & 166 & 100 & - & 166 & 100 \\
\hline
\end{tabular}

Do ponto de vista da faixa etária, predominam os respondentes entre 20 e 25 anos, com 77 registros, equivalente a 46\%. Quanto à relação entre os percentuais de gênero masculino e feminino, os dados são coerentes com a realidade nacional e também com o número de eleitores (48\%) e eleitoras (52\%), segundo dados do Tribunal Superior Eleitoral. ${ }^{8}$

Quanto à distribuição por ano, a Tabela 2 mostra um relativo equilíbrio no número de respondentes de cada uma das edições do PJB, com o menor percentual, de 19\%, em 2010, e o maior, de 41\%, em 2013.

\footnotetext{
7 As porcentagens estão arredondadas para mais quando têm casa decimal maior do que 0,5 e para menos quando menor.

${ }^{8}$ Disponível em: http://www.tse.jus.br/eleitor/estatisticas-de-eleitorado/estatistica-do-eleitorado-por-sexo-e-faixa-etaria.
} 
Mesmo quando se tratam dos percentuais menores, a amostragem pode ser considerada representativa do universo de egressos.

Tabela 2. Quantitativo das amostras por edição

\begin{tabular}{c|c|c|c}
\hline Edição & Amostra & População & Porcentagem \\
\hline 2006 & 17 & 78 & $21,79 \%$ \\
\hline 2007 & 29 & 77 & $37,66 \%$ \\
\hline 2008 & 20 & 78 & $25,64 \%$ \\
\hline 2009 & 17 & 65 & $26,15 \%$ \\
\hline 2010 & 15 & 77 & $19,48 \%$ \\
\hline 2011 & 20 & 81 & $24,69 \%$ \\
\hline 2012 & 16 & 70 & $22,86 \%$ \\
\hline 2013 & 32 & 79 & $40,51 \%$ \\
\hline Total & 166 & 605 & $27,43 \%$ \\
\hline
\end{tabular}

Fonte: Elaboração dos autores.

Os egressos que responderam à pesquisa residem, em grande parte, em cidades do interior (62\%) e os demais em capitais, com predomínio de residentes nas regiões Sudeste, Nordeste e Sul, como mostra a Tabela 3. Uma informação complementar relevante é de que a amostragem de egressos segmentada conforme a região geográfica é relativamente coerente com a distribuição do eleitorado regional ${ }^{9}$.

A quantidade de vagas do projeto é proporcional ao quantitativo de cadeiras na Câmara dos Deputados que, por sua vez, está vinculada à população dos estados brasileiros. Conforme pode ser verificado na Tabela 3, a realização da pesquisa resultou numa proporção muito próxima entre a amostra e a população de eleitores das regiões, com leve diferença em algumas e um maior percentual na amostra do Sudeste. Considera-se

${ }_{9}$ Disponível em: http://www.tse.jus.br/eleitor/estatisticas-de-eleitorado. 
assim que os dados levantados têm uma boa representatividade do perfil dos egressos do PJB.

Tabela 3. Comparação da amostra dos egressos e população de eleitores

\begin{tabular}{c|c|c|c|c|c}
\hline Região & $\mathbf{N}$ & $\begin{array}{c}\text { Amostra em } \\
\text { relação à } \\
\text { população de } \\
\text { egressos }\end{array}$ & $\begin{array}{c}\text { Proporção da po- } \\
\text { pulação brasileira } \\
\text { por região }\end{array}$ & $\begin{array}{c}\text { Eleitores } \\
\mathbf{N}\end{array}$ & $\begin{array}{c}\text { Eleitores } \\
\%\end{array}$ \\
\hline Norte & 15 & $8,44 \%$ & $8,88 \%$ & 10.704 .517 & 7,55 \\
\hline Sudeste & 66 & $39,75 \%$ & $40,83 \%$ & 61.233 .192 & 43,21 \\
\hline $\begin{array}{c}\text { Centro- } \\
\text {-Oeste }\end{array}$ & 19 & $7,45 \%$ & $11,24 \%$ & 10.266 .708 & 7,24 \\
\hline Nordeste & 39 & $27,75 \%$ & $23,67 \%$ & 38.388 .087 & 27,09 \\
\hline Sul & 26 & $14,32 \%$ & $15,38 \%$ & 20.810 .471 & 14,68 \\
\hline Exterior & 1 & $0,60 \%$ & $\mathrm{~N} *$ & 296.157 & 0,20 \\
\hline Total & 166 & 100 & 100 & 141.699 .132 & 100 \\
\hline
\end{tabular}

Fonte: Elaboraçao dos autores, com dados do $15 t$ - Estatistica de eleitorado em 2015.

*Os dados da quantidade de brasileiros residentes no exterior são muito discrepantes entre os diferentes órgãos, dessa forma, nesta tabela as porcentagens da população estão apresentadas desconsiderando-se esse grupo.

Em relação à formação educacional dos egressos, grande parte dos respondentes está em processo de graduação ou já se formou ${ }^{10}(69 \%)$. Quando se separam apenas aqueles graduados ou graduandos em ciências humanas ou sociais aplicadas chega-se a um percentual de $48 \%$ do total da amostra. ${ }^{10}$ Cabe ressaltar que os dados se referem ao momento em que os egressos responderam o
questionário e não ao período em que participaram do PJB. 
Tabela 4. Escolaridade dos egressos

\begin{tabular}{l|c|c}
\hline Formação & Quantitativo de respostas & Proporções da amostra \\
\hline Médio e técnico & 33 & $19,87 \%$ \\
\hline Graduação & 114 & $68,67 \%$ \\
\hline Pós-graduação & 19 & $11,44 \%$ \\
\hline Total & 166 & 100 \\
\hline
\end{tabular}

Fonte: Elaboração dos autores.

\section{A confiança no Poder Legislativo e nos partidos políticos}

A variação da confiança em relação ao Poder Legislativo foi sensível. Foi perguntado qual seria o nível de confiança antes e, em outra questão, qual passou a ser o nível de confiança após o PJB, com ambas as questões respondidas no mesmo questionário. Fica evidente nos resultados uma variação significativa da confiança, enquanto que a maioria dos egressos considera seu nível de confiança no Legislativo, antes do PJB, nos dois menores níveis (51\%), após a simulação parlamentar $87 \%$ se identificam com os dois maiores níveis.

Tabela 5. Confiança no Poder Legislativo antes e após o PJB

\begin{tabular}{|c|c|c|c|c|c|}
\hline Confiança antes & $\mathrm{N}$ & $\%$ & Confiança após & $\mathrm{N}$ & $\%$ \\
\hline nenhuma & 16 & 9,63 & Nenhuma & 3 & 1,80 \\
\hline quase nenhuma & 69 & 41,56 & quase nenhuma & 18 & 10,84 \\
\hline alguma & 76 & 45,78 & alguma & 97 & 58,43 \\
\hline muita & 5 & 3,01 & Muita & 48 & 28,91 \\
\hline
\end{tabular}


Um dado relevante deste levantamento é o fato de que apenas $4 \%$ dos egressos tiveram uma variação negativa e outros 37\% afirmaram que não houve variação da confiança, contudo $58 \%$ variaram positivamente, em diferentes graus, a confiança no Poder Legislativo. Esse resultado aponta para a inversão de uma lógica comum também ao eleitorado em geral, no qual se verifica um baixo nível de confiança no Parlamento, sendo que, numa escala de 0 a 100, o IBOPE (2014) encontrou 35 pontos para a confiança no Congresso Nacional, o que, comparado a outras instituições sociais, perde apenas para os partidos políticos, que têm a menor pontuação (30). Para efeito de comparação, transpondo-se a escala utilizada de quatro níveis de confiança deste estudo para uma escala centesimal ${ }^{11}$, verifica-se aproximadamente 47 pontos como percepção para o período anterior e 71 pontos após a participação, o que indica um aperfeiçoamento considerável do nível de confiança dos jovens no Poder Legislativo. O fator gênero não apresentou diferença significativa quando correlacionado com o nível de confiança no Poder Legislativo. De forma semelhante ao fator gênero, o nível educacional não indicou forte relação com o nível de confiança pós-PJB.

Como forma de avaliar se os egressos com maior tempo decorrido da participação no projeto teriam menor confiança no Legislativo, foram agrupados os dois menores níveis e também os dois maiores, conforme pode ser visualizado no Gráfico 1.

Transposição realizada da seguinte forma: nenhuma confiança $=0$, quase nenhuma $=$ 33,33 , alguma $=66,66$ e muita $=100$. 
Gráfico 1. Confiança no Poder Legislativo por edição

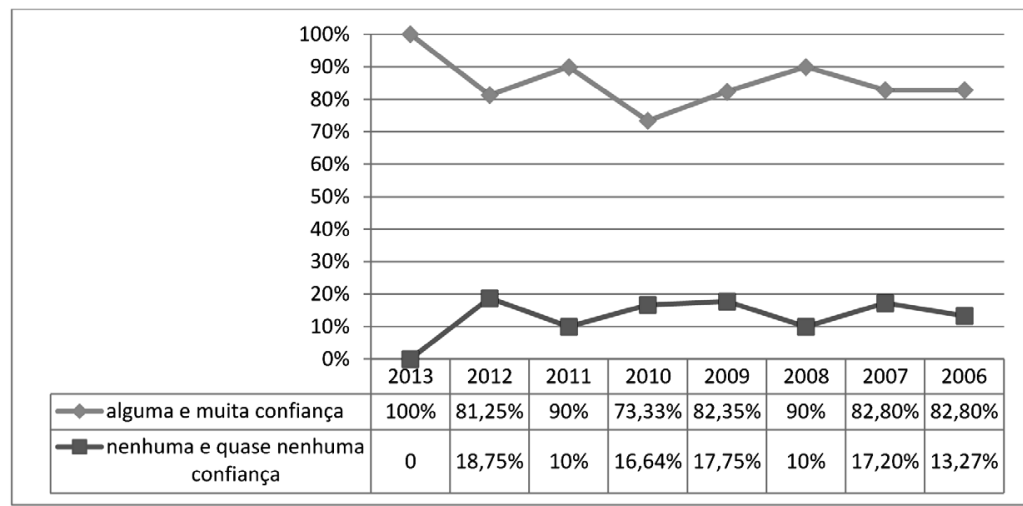

Fonte: elaboração dos autores.

Por meio dessa análise é possível perceber certa manutenção dos níveis de confiança no Poder Legislativo com o passar dos anos decorridos da participação no projeto, apesar de uma leve diminuição dessa confiança dos egressos nos quatro anos posteriores à participação. Um quantitativo a ser destacado é o de que 29\% (48 respostas) dos egressos em geral afirmaram ter muita confiança no Poder Legislativo após o PJB, o que demonstra um efeito significativo, já que apenas cinco afirmaram ter muita confiança no Parlamento em relação ao período anterior ao projeto $(3 \%)$.

\section{Confiança nos partidos políticos}

Outra temática da pesquisa em questão é o nível de confiança dos egressos nos partidos políticos, já que esse é um fator com possível influência na participação política institucionalizada. Foi perguntado aos egressos qual seria o nível de confiança que eles teriam antes de participar do projeto e qual o nível após o PJB (alternativas - nenhuma, quase 
nenhuma, alguma e muita confiança). Para $49 \%$ dos respondentes a confiança aumentou, em diferentes graus, $42 \%$ mantiveram-se como antes e outros $9 \%$ diminuíram sua confiança nos partidos.

Apesar de ficar visível uma diminuição do nível da confiança conjuntamente com o tempo decorrido da participação, é possível constatar certa constância da confiança nas instituições partidárias tendo-se como referência os dois maiores e menores níveis. É importante destacar a predominância de respostas nos dois graus intermediários - quase nenhuma confiança (23\%) e alguma confiança (56\%).

Gráfico 2. Confiança nos partidos políticos após o PJB por ano da edição

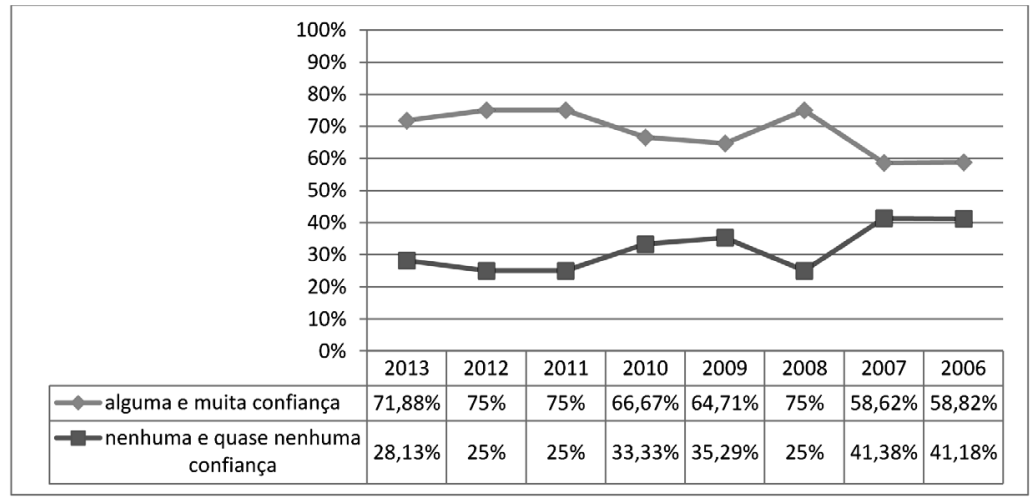

Fonte: Elaboração dos autores. 
Sociologias, Porto Alegre, ano 19, no 46, set/dez 2017, p. 392-426

Gráfico 3. Motivação para participar da política via partidos políticos

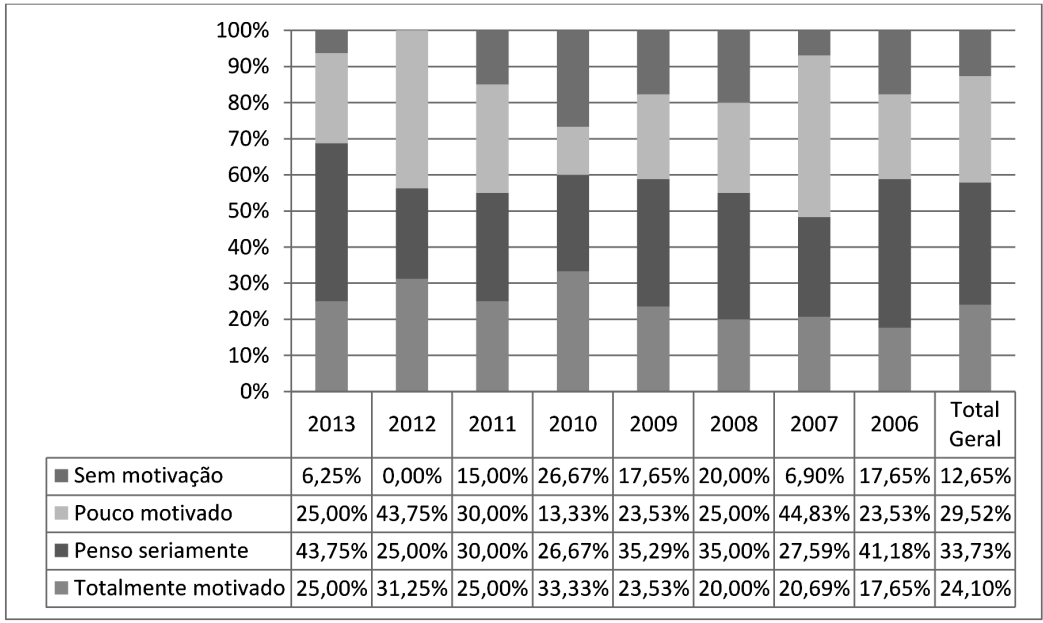

Fonte: Elaboração dos autores.

O nível educacional dos egressos não apresentou relação relevante com essa motivação, porém é possível perceber um maior quantitativo de egressos formados ou formandos em ciências humanas ou sociais aplicadas, que tem maior interesse pela política institucional.

Conforme preceitos da teoria da cultura cívica, a confiança é fator preponderante para a participação no contexto democrático (Almond; Verba, 1965). Nesse sentido, o cruzamento do nível de confiança dos egressos e da motivação para a participação institucional em partidos políticos pode dar-nos uma perspectiva de análise mais aprofundada, conforme demonstrado na Tabela 6. 
Sociologias, Porto Alegre, ano 19, no 46, set/dez 2017, p. 392-426

Tabela 6. Cruzamento de dados - confiança após o PJB e motivação para participar dos partidos políticos

\begin{tabular}{c|c|c|c|c|c|c|c|c}
\hline & \multicolumn{6}{|c}{ Motivaça atual para participar de partidos } \\
\hline $\begin{array}{c}\text { Confiança nos } \\
\text { partidos após } \\
\text { o PJB }\end{array}$ & \multicolumn{2}{|c|}{$\begin{array}{c}\text { sem } \\
\text { motivação }\end{array}$} & \multicolumn{2}{c}{$\begin{array}{c}\text { pouco } \\
\text { motivado }\end{array}$} & \multicolumn{2}{c}{$\begin{array}{c}\text { penso } \\
\text { seriamente }\end{array}$} & $\begin{array}{c}\text { totalmente } \\
\text { motivado }\end{array}$ \\
\hline nenhuma & 3 & $1,81 \%$ & 7 & $4,22 \%$ & 3 & $1,81 \%$ & 2 & $1,20 \%$ \\
\hline quase nenhuma & 7 & $4,22 \%$ & 17 & $10,24 \%$ & 10 & $6,02 \%$ & 4 & $2,41 \%$ \\
\hline alguma & 10 & $6,02 \%$ & 20 & $12,05 \%$ & 39 & $23,49 \%$ & 25 & $15,06 \%$ \\
\hline muita & 1 & $0,60 \%$ & 5 & $3,01 \%$ & 4 & $2,41 \%$ & 9 & $5,42 \%$ \\
\hline Fonte: elaboração dos autores.
\end{tabular}

Aqueles egressos que têm maior confiança nos partidos políticos apresentam também maior motivação de participar dessas instituições. Essa afirmação se baseia no cruzamento dos dois maiores níveis de confiança com os dois maiores de motivação, que somam 77 egressos (46\%). A inversão dos quesitos também abarca parte considerável dos egressos, já que aqueles com menor motivação e menor confiança reúnem 20\%. Os que possuem menor confiança, junto aos que, ao contrário, têm maior motivação somam apenas $11 \%$. Em contraponto, verifica-se um percentual de $22 \%$ de egressos que se encontram nos dois maiores níveis de confiança nos partidos, porém também indicaram ter pouco ou nenhuma motivação para essa ação.

O Índice de Confiança Social (ICS) elaborado pelo IBOPE indica os partidos políticos como a instituição com menor credibilidade entre os cidadãos brasileiros, sendo que, numa escala de 100 pontos, em 2014, sua credibilidade marcou 30. Como forma de comparação desses dados com o nível de confiança dos jovens egressos em relação aos partidos e os 4 níveis sugeridos por este estudo, quando transpostos para uma escala numérica de 100 pontos, o nível médio encontrado para o período antes do PJB é 39; 
já para o período posterior ao PJB, a confiança aumenta consideravelmente para 57 pontos, o que aproxima a confiança nos partidos políticos à de outras instituições verificadas no índice do IBOPE como 'meios de comunicação' (54), escolas públicas (56) e forças armadas (62) '12.

Apesar das diferenças metodológicas e de escala na verificação da confiança da população em geral e do PJB, fica evidente uma larga diferença dos resultados do índice e da confiança dos egressos em relação ao período posterior ao projeto, apontando para um perfil de opinião diferenciado dos egressos a partir da participação na simulação parlamentar do PJB. Nesse sentido, a comparação das respostas acerca do nível de confiança nos partidos antes e após o PJB indicam um crescimento relevante desse sentimento, conforme pode ser verificado na Tabela7, a seguir.

Tabela 7. Nível de confiança dos egressos nos partidos antes e depois do PJB

\begin{tabular}{c|c|c|c|c|c}
\hline Antes do PJB & $\mathbf{N}$ & $\mathbf{\%}$ & Depois do PJB & $\mathbf{N}$ & $\mathbf{\%}$ \\
\hline $\begin{array}{c}\text { Nenhuma } \\
\text { confiança }\end{array}$ & 34 & 20,48 & $\begin{array}{c}\text { Nenhuma } \\
\text { confiança }\end{array}$ & 15 & 9,04 \\
\hline $\begin{array}{c}\text { Quase nenhuma } \\
\text { confiança }\end{array}$ & 73 & 43,98 & $\begin{array}{c}\text { Quase nenhuma } \\
\text { confiança }\end{array}$ & 38 & 22,89 \\
\hline $\begin{array}{c}\text { Alguma } \\
\text { confiança }\end{array}$ & 54 & 32,53 & $\begin{array}{c}\text { Alguma } \\
\text { confiança }\end{array}$ & 94 & 56,63 \\
\hline $\begin{array}{c}\text { Muita } \\
\text { confiança }\end{array}$ & 5 & 3,01 & $\begin{array}{c}\text { Muita } \\
\text { confiança }\end{array}$ & 19 & 11,45 \\
\hline Fonte: Etaboraçao dos autores.
\end{tabular}

$\overline{12}$ Dados do Índice de Confiança Social do IBOPE, 2013. 


\subsection{Estímulo do PJB ao interesse para candidatura a cargos políticos}

Foi indagado também se a participação no PJB havia gerado interesse no participante em candidatar-se, com alternativas binárias (sim ou não), sendo que $38 \%$ dos egressos responderam positivamente. No gráfico 4 , a seguir, fica clara uma forte diminuição da percepção desse estímulo com o passar dos anos transcorridos da participação, tendo a turma mais recente (2013) apontado pouco mais de 53\% de jovens estimulados, já no último ano analisado (2006) apenas cerca de18\% confirmaram este estímulo.

Gráfico 4. Interesse em se candidatar gerado pelo PJB por ano

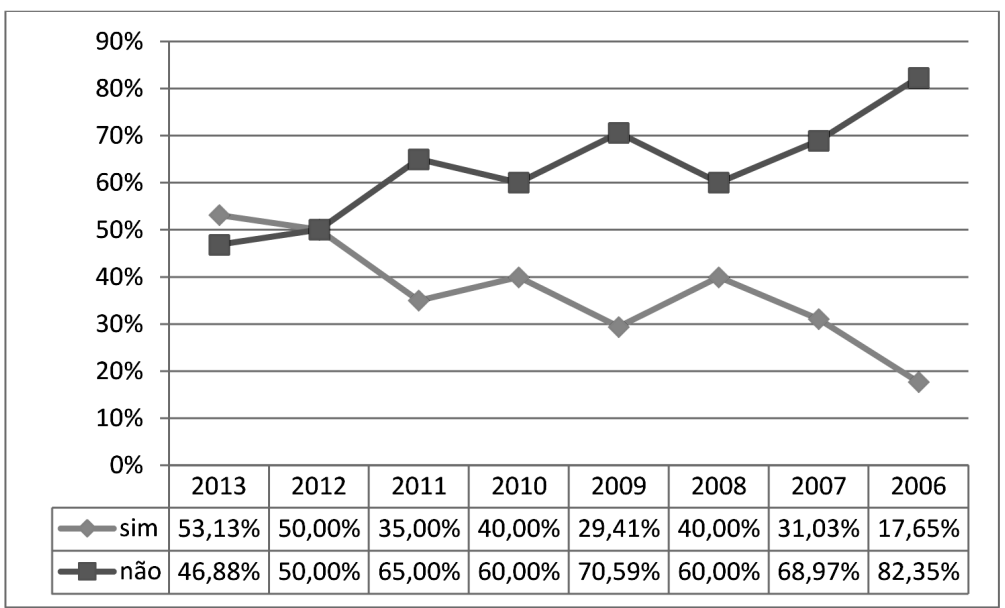

Fonte: Elaboração dos autores. 
O público masculino demonstrou maior estímulo para candidaturas com mais de $51 \%$ de respostas positivas neste grupo, contra $24 \%$ de respostas para o público feminino. O parâmetro moradia indicou um interesse levemente superior para os residentes nas cidades do interior, 22\% contra $16 \%$ entre os que residem nas capitais.

Outro dado relevante, nesse contexto analítico, diz respeito à participação em campanhas eleitorais. Entre os egressos, 23\% "participam atualmente" das campanhas em seus estados de origem. Entretanto, 47\% dos egressos nunca se envolveu diretamente nessa atividade política, sendo que a participação feminina é bastante inferior em termos quantitativos do que o público masculino estudado. Entre as mulheres, $63 \%$ nunca se envolveu nessa atividade, enquanto que apenas $34 \%$ dos homens nunca desenvolveu atividades políticas eleitorais. Isso mostra que as campanhas não são atrativas para a juventude, principalmente para as mulheres, mesmo tratando-se aqui de um público com um perfil de opinião e formação política diferenciado do eleitoral em geral.

\section{Conclusões}

A partir da análise das respostas dos egressos de oito edições do PJB, é possível afirmar que a participação nas atividades formativas e também de simulação parlamentar interferem significativamente na confiança em relação ao Poder Legislativo e aos partidos políticos, o que também se relaciona diretamente com a maior motivação identificada para participar da política via partidos políticos. A falta de conhecimento acerca do perfil anterior dos participantes dificulta a confirmação empírica de alguns fenômenos analisados, porém uma simples comparação do perfil do eleitorado em geral com as opiniões e interesses dos egressos pode dar-nos pistas para o entendimento dos efeitos do projeto. Pesquisa do Senado 
Federal (BRASIL, 2014a), com amostragem nacional, apontou que 15\% da população já pensou seriamente em se candidatar ou já se candidatou (3\%). Ao observar que cerca de $38 \%$ dos egressos afirmou que o projeto gerou interesse em candidaturas a cargos políticos, já é possível visualizar alguma diferença, o que é reforçado pela idade desse público, nessa pesquisa, de 17 a 29 anos, e no eleitorado de 18 até o eleitor mais idoso.

Enquanto estudos apontam que apenas 1,4\% de jovens ingressam em partidos (Telles; Dias, 2010), o comportamento dos egressos do PJB parece ser bastante diferente, já que $17 \%$ estão filiados a partidos e atuantes, sendo que outros $7 \%$ se filiaram após o PJB mas pararam de participar e cerca de $10 \%$ já eram filiados antes de participarem do projeto. Assim, fica evidente um efeito direto do projeto no nível da ativação (o que é reforçado pelo comportamento e atitude nos primeiros anos posteriores ao projeto em diferentes quesitos analisados) e também no reforço da participação na política institucional. É provável que experiências de educação política e simulação parlamentar, como o PJB, tenham o potencial de, em grande medida, reverter a lógica conjuntural de desconfiança quanto ao Poder Legislativo e aos partidos políticos, e do subsequente afastamento do público jovem dessa esfera.

O PJB, mais do que iniciar muitos desses jovens, que chegam a Brasília sem grande envolvimento ou conhecimento político, tem o potencial de formar jovens líderes, o que de fato tem ocorrido, pela candidatura de egressos a cargos políticos (dado ainda a ser mensurado) e, como exemplo, pela eleição para vereador de dois jovens - Ayron Freixo no município de Arraial do Cabo/RJ (egresso da edição de 2004) e Lívia Guimarães Souza no município de Rio das Ostras/RJ (egressa da edição de 2005). Durante a busca dos contatos dos egressos para a realização deste estudo, realizada principalmente pela internet, percebeu-se que a participação no projeto, desde a aprovação dos jovens, gera uma ampla repercussão 
e reconhecimento desse cidadão, o que vai muito além do ambiente escolar, difundindo-se em veículos jornalísticos locais e também no meio político regional, inclusive nas câmaras de vereadores, sendo que, em muitos casos, são realizadas homenagens em sessões públicas direcionadas aos egressos.

Os dados mostram que o PJB altera significativamente a visão dos jovens acerca da política, interfere, em muitos casos, nos anseios de posicionamento social e na escolha de profissões, conforme dados gerais da pesquisa $^{13}$. É possível perceber, em muitos casos, uma mudança da percepção da possibilidade de interferência na realidade, ou seja, gera a ativação da cidadania e da visão crítica acerca da política. Uma análise qualitativa mais detalhada das respostas abertas dos egressos, neste mesmo levantamento ${ }^{14}$, poderá ampliar esse conhecimento acerca dos efeitos do PJB. Para efeitos ilustrativos da análise desse recorte acerca da confiança e interesse em participar, relata-se apenas um trecho de uma resposta de um egresso da edição de 2006, atualmente filiado a um partido político: "Minha participação no PJB me tornou um jovem com mais coragem para assumir de vez a política e lutar para que ela seja exercida com qualidade, respeito, ética, democracia e participação popular" (J.M.O., masculino, edição 2006, residente em cidade do interior do Rio Grande do Sul).

A importância da educação para a democracia representada pelo PJB reside justamente no impacto positivo na cultura cívica dos jovens, ou seja, na ampliação do conhecimento e da confiança nas instituições políticas mantenedoras da democracia representativa, com destaque para o Poder Legislativo e os partidos políticos. Conforme apresentado no item anterior deste artigo, a participação no PJB alterou o nível de confiança atribuída aos partidos, mesmo a iniciativa educativa não tendo foco nessa

\footnotetext{
13 Aqui nos reportamos aos dados mais abrangentes, pois o questionário aplicado é mais amplo do que o recorte selecionado para este artigo.

${ }^{14}$ A análise qualitativa das respostas abertas será objeto de outro artigo.
} 
temática, já que o direcionamento da simulação é para os procedimentos e atuação parlamentar no processo legislativo, sem uma partidarização obrigatória. Entretanto, as atividades incluem diversas oportunidades de debate de ideias que, naturalmente, geram a formação de grupos favoráveis e contrários, seja para aprovação/rejeição de propostas, seja na eleição dos cargos da mesa diretora do Parlamento Jovem.

A pesquisa também identificou um aumento do acompanhamento das atividades legislativas, do horário eleitoral gratuito, do noticiário político e da interação sobre política em redes sociais, dados que serão apresentados de forma detalhada em estudo específico acerca da participação não institucional, já que esta temática tem gerado interesse de diversos estudiosos, haja vista uma possível tendência de mudança do perfil de participação política juvenil para meios alternativos.

Além da identificação do crescimento da confiança institucional e de reforço e ativação do engajamento e da participação, este estudo indica também que esses efeitos podem ser, em grande medida, duradouros, o que reitera a importância desse tipo de estratégia institucional do Poder Legislativo. O resultado do projeto analisado não afeta apenas o âmbito individual e cognitivo dos participantes, também envolve e gera importância para a temática da formação política juvenil entre as instituições parceiras na execução do mesmo, gera repercussão nos ambientes familiares, escolares e nas localidades de origem desses jovens. De forma indireta, os partidos políticos interagem com o PJB, ao motivar a participação de jovens filiados, ao valorizar essa participação nas câmaras de vereadores e assembleias legislativas por todo o País e ao agregar parte dos egressos aos seus quadros e às ações de mobilização política.

É possível afirmar que o Parlamento Jovem Brasileiro, a partir de resultados relatados por seus egressos, fortalece a democracia, ao ampliar a cultura cívica de jovens de diversas partes do país, que passam a ter uma 
opinião mais esclarecida acerca da política e se envolvem de forma diferenciada em atividades políticas não institucionais e nos partidos políticos.

Antonio Teixeira de Barros é doutor em Sociologia pela UnB. Docente e pesquisador do Mestrado em Poder Legislativo do Centro de Formação da Câmara dos Deputados (Brasil) \antonibarros@gmail.com

Lúcio Meireles Martins é Mestre em Poder Legislativo pelo Centro de Formação da Câmara dos Deputados (Brasil) \luciogoiano@hotmail.com

\section{Referências}

1. ALMOND. G.; VERBA, S. The Civic Culture. Political attitudes and democracy in five nations. Boston: Little, Brown and Company, 1965.

2. BORDENAVE, J. E. D. O que é participação? São Paulo: Brasiliense, 2002.

3. BAPTISTA, É. A. et al. Jovens eleitores e novas tecnologias: percepções da política e participação. Revista do Legislativo. Belo Horizonte, v. 5, n. 1, jan. 2013, p.124-32.

4. BRASIL. Mulheres na política. Secretaria de Transparência. Coordenação de Controle Social. Serviço de Pesquisa DataSenado. Brasília: Senado Federal, set. 2014a.

5. BRASIL. Diminui o número de filiados a partidos políticos. Matéria jornalística. Brasília: Senado Federal, 30 de set. 2014b. Disponível em: http://www12.senado.gov.br/jornal/edicoes/2014/09/30/diminui-o-numero-de-filiados-a-partidos. Acesso em: 27 nov. 2014.

6. BOSCHI, R. Instituições políticas, reformas estruturais e cidadania: dilemas da democracia no Brasil. In: SEMINÁRIO Internacional Sobre Democracia na América Latina, 2004, Santiago. Anais... Chile, 2004.

7. CASTRO, M. M.M. Sujeito e estrutura no comportamento eleitoral. Revista Brasileira de Ciências Sociais, Rio de Janeiro, v. 20, p. 7-19, 1992.

8. CASTRO, L. R. Juventude e socialização política: atualizando o debate. Psicologia: Teoria e Pesquisa, v. 25, n. 4, 2009, p. 479-87. 
9. CASTRO, L. R. Participação política e juventude: do mal-estar à responsabilização frente ao destino comum. Revista Sociologia Política. Curitiba, v. 16, n. 30, pp. 253-68. 2008.

10. COLEN, M. C. L. As covariantes da confiança política na América Latina. Opinião Pública, Campinas, v. 16, n. 1, 2010, p. 1-27.

11. DAHL, R. Um prefácio à teoria democrática. Rio de Janeiro: J. Zahar, 1989.

12. DALTON, R. J. Democratic challenges, democratic choices: the erosion of political support in advanced industrial democracies. Oxford: Oxford University Press, 2007.

13. DAYRELL, J.; MOREIRA, M. I. C.; STENGEL, M. Juventude contemporâneas: um mosaico de possibilidades. In: Anais do Simpósio Internacional sobre Juventude Brasileira. Belo Horizonte: PUCMG, 2011.

14. FERES Jr., J.; EISENBERG, J. Dormindo com o Inimigo: Uma Crítica ao Conceito de Confiança. Dados - Revista de Ciências Sociais. Rio de Janeiro, v. 49, n. 3, p. 457-82.

15. GOHN, M. G. Os jovens e as praças dos indignados: territórios de cidadania. Revista Brasileira de Sociologia, v. 1, n. 2, p.205-21, jul/dez 2013.

16. GIDDENS, A. As consequências da modernidade. São Paulo: Unesp, 1990. 17. GOMES, W. Transformação da Política na era da comunicação de massa. São Paulo: Paulus, 2004.

18. GOMES, M. B. Hermenêutica, teoria política e imagem pública. Anais do I Congresso da Associação Brasileira de Pesquisadores em Comunicação e Política. Salvador, nov. 2006. Disponível em: http://www.compolitica.org/ home/?page_id=70. Acesso em: 4 mar. 2015.

19. IBOPE. Após queda acentuada em 2013, Índice de Confiança Social se estabiliza. Matéria jornalística (sem citação de autor). 1o set. 2014. Disponível em: http://www.ibope.com.br/pt-br/noticias/Paginas/Ap\%C3\%B3s-queda-acentuadaem-2013, Indice-de-Confianca-Social-se-estabiliza.aspx. Acesso em: 28 fev. 2015.

20. JOSHI, D.; ROSENFIELD, E. MP. Transparency, Communication Links and Social Media: a comparative assessment of 184 Parliamentary Websites. The Journal of Legislative Studies, v. 19, n. 4, p. 526-45.

21. LESTON-BANDEIRA, C. Studying the relationship between Parliament and citizens. The Journal of Legislative Studies, v. 18, n. 3-4, set./dez. 2012, p. 26574.

22. LIJPHART, A. Democracy in the 21st Century: Can We Be Optimistic? European Review, v. 9, n. 2, p. 169-84, 2001. 
23. LOPES, D. M. N. N. Para pensar a confiança e a cultura política na América Latina. Opinião Pública, v. 10, n. 1, Campinas, 2004, p.162-87.

24. MAYORGA, C.; CASTRO, L. R.; PRADO, M. A. M. Juventude e a experiência da política no contemporâneo. Rio de Janeiro: Contra Capa Editora, 2012.

25. MALFITANO, A. P. S. Juventudes e contemporaneidade: entre a autonomia e a tutela. Etnográfica, v. 15, n. 3, Lisboa, 2011, pp. 523-42.

26. MIGUEL, L. F. Representação política em 3-D. Elementos para uma teoria ampliada da representação política. Revista Brasileira de Ciências Sociais. v. 18, n. 51, fev. 2003, p. 123-40.

27. MIGUEL, L. F. Impasses da accountability: dilemas e alternativas da representação política. Revista de Sociologia Política, n. 25, Curitiba, nov. 2005, p. 25-38.

28. MIGUEL, L. F. A mídia e o declínio da confiança na política. Sociologias, v. 10, n. 19, Porto Alegre, jan./jun. 2008, p. 250-73.

29. MILBRATH, L. W.; GOEL, M. L. Political Participation: How and Why Do People Get Involved in Politics? Chicago: Rand McNally College Pub. Co., 1977.

30. MOISÉS, J. A. Democracia e desconfiança de instituições democráticas. Edição do autor, 2009.

31. NASCIMENTO, M. R. Parlamento Jovem, juventudes e participação política. In: MEDEIROS, R. de P.; MARQUES, M. E. Educação política da juventude: a experiência do parlamento jovem. Belo Horizonte: Editora PUC Minas, 2012, p.305-325.

32. NORRIS, P. Critical citizens: global support for democratic government. USA: Oxford University Press, 1999.

33. NORRIS, P. Democratic Deficit - Critical Citizens Revisited.Cambridge University Press, 2011.

34. NORRIS, P. Young People \& Political Activism: From the Politics of Loyalties to the Politics of Choice? Report for the Council of Europe Symposium, 2003. Disponível em: http://www.pipanorris.com. Acesso em: 30 maio 2014.

35. OFFE, C. How can we trust our fellow citizens? In: WARREN, M. E. (Ed.). Democracy and Trust. Cambridge: Cambridge University Press, 1999.

36. OKADO, L. T. A. 2013. Juventude e participação política no Brasil: efeitos geracionais ou de ciclos de vida. Revista Espaço Acadêmico, v. 13, n. 147, ago. 2013, p. 37-50. 
37. PAIVA, I. A. Da reprodução social à criação de oportunidades de vida: Juventude, protagonismo e educação em assentamentos rurais. Tese (Doutorado em Educação) - Universidade de São Paulo, São Paulo, 2010. 208pp.

38. PORTO, M. A crise de confiança política e suas instituições: os mídia e a legitimidade da democracia. In: BAQUERO, Marcello (Org.). Condicionantes da consolidação democrática: ética, mídia e cultura política. Porto Alegre: Editora da UFRGS, 1996.

39. POWER, T. J.; JAMINSON, G. D. Desconfiança política na América Latina. Opinião Pública, Campinas, v. 11, n. 1, mar. 2005, p.64-93.

40. RIBEIRO, E.; LANES, P.; CARRANO, P. Diversidade de perfis caracteriza as juventudes brasileiras. Ibase, 2006. Disponível em: http://www.ibase.br/userimages/ibasenet_dv30_indicadores.pdf. Acesso em: 30 jun. 2014.

41. RIBEIRO, E. A. Participação Política e Juventude: mudanças no padrão de relacionamento entre os cidadãos e a política. Em Debate, Belo Horizonte, v. 4, n. 8, p. 26-34, nov. 2013.

42. RIQUE, J. et al. Questões sociais e engajamento dos jovens na vida sociopolítica. Gerais: Revista Interinstitucional de Psicologia, v. 2, n 2, p.141 - 150, julho-dez de 2009.

43. RODRIGUES, Alan. O que os jovens pensam sobre a política. Revista IstoÉ. n. 2336, 29 ago. 2014. Disponível em: http://www.istoe.com.br/reportagens/380009_O+QUE+OS+JOVENS+PENSAM+SOBRE+A+POLITICA. Acesso em: 13 jañ. 2015.

44. RIBEIRO, Ednaldo E. A. Confiança política na América Latina: evolução recente e determinantes individuais. Revista de Sociologia e Politica, v. 19, n. 39. Curitiba, 2011, p. 167-82.

45. STOKER, G. Why Politics Matters: Making Democracy Work. Basingstoke: Palgrave Macmillan, 2006.

46. TELLES, H. de S.; DIAS, M. Condutas políticas, valores e voto dos eleitores jovens de Belo Horizonte. Revista do Legislativo, n. 43, Belo Horizonte, jan. 2010, p. 82-102.

47. THOMPSON, J. B. Ideologia e cultura moderna. Petrópolis: Vozes, 1995.

48. TILLY, C. Democracy. New York: Cambridge University Press, 2008.

49. ZITKOSKI, J. J.; HAMMES, L. J. Juventude, educação e cidadania: os desafios da participação social e política. Debates, v.8, n.2. Porto Alegre, maio/ago, 2014, p. 119-39.

Recebido: 29.06.2015

Aceite final: 03.08.2016 